\title{
STATE-DEPENDENT VULNERABILITY OF CASE-STUDY REINFORCED CONCRETE FRAMES
}

\author{
Karim Aljawhari ${ }^{1}$, Fabio Freddi ${ }^{1}$ and Carmine Galasso ${ }^{1}$ \\ ${ }^{1}$ Department of Civil, Environmental \& Geomatic Engineering, University College London \\ Chadwick Building, Gower Street, London, WC1E 6BT \\ karim.aljawhari.16@ucl.ac.uk, f.freddi@ucl.ac.uk, c.galasso@ucl.ac.uk
}

\begin{abstract}
This study investigates the effect of mainshock-aftershock sequences on numerical fragility and vulnerability relationships of European reinforced concrete $(R C)$ moment-resisting frames (MRFs). A four-story, four-bay nonductile RC MRF is selected for illustrative purposes. This index building is representative of a typical vulnerability class in the Mediterranean region. The influence of the masonry infills on seismic performance is also investigated. An advanced numerical nonlinear model is developed for the case-study frame and then assessed through nonlinear dynamic analysis using both real and artificial mainshock-aftershock sequences, via a 'sequential cloud' approach. The obtained seismic demand estimates allow to generate fragility functions for the undamaged frame when subjected to mainshocks only. Moreover, statedependent fragility functions are derived for the mainshock-damaged frame when subsequently subjected to aftershocks. Damage-to-loss models, specifically calibrated on Italian post-earthquake data, are used to derive vulnerability functions for this case-study structure. Preliminary results from the study show that the frame experiences severe damages states and high losses for a range of ground-motion shaking intensities, with a clear damage increase due to aftershocks. An attempt to generate vector-valued mainshock-aftershock vulnerability relationships is finally presented. The proposed vulnerability surfaces can be more easily implemented into a time-dependent risk assessment framework.
\end{abstract}

Keywords: Mainshock-aftershocks sequences; Seismic performance; Fragility curves; Vulnerability curves; Reinforced concrete frames; Masonry infills. 


\section{INTRODUCTION}

Earthquakes typically occur in sequences. Most often, each sequence is dominated by a seismic event with a larger magnitude than all others in the sequence. Such major seismic events constitute mainshocks, generally followed by several aftershocks clustered in both space and time. Earthquake sequences can cause huge losses due to repair costs, business interruption and casualties, especially if affected structures are left unrepaired after experiencing an initial damage due to the mainshock.

Recent events worldwide have demonstrated the extent to which the effect of such sequential earthquake-induced ground shaking can be devastating. On September 2010, the city of Christchurch, in New Zealand, was hit by a mainshock with a moment magnitude $\left(M_{\mathrm{w}}\right)$ of 7.1 which was followed, on February 2011, by a $M_{\mathrm{w}} 6.3$ aftershock. The seismic sequence resulted in approximately 185 casualties and $\$ 15$ billion financial losses [1]. After the September mainshock, $90 \%$ of the reinforced concrete (RC) frames were classified as safe to re-occupy with none or minor damage in the central business district in Christchurch [2]. Following the aftershock of February 2011, only 53\% were classified as safe to re-occupy, whilst the portion of unsafe buildings raised significantly to $18 \%$ and approximately $29 \%$ were either demolished or had limited accessibility [2].

A similar situation was observed during the recent 2016-17 Central Italy earthquake sequence. This sequence consisted of several moderate-to-high magnitude earthquakes, each centered in a different location and with its own sequences of aftershocks spanning several months (e.g., [3]). The first event of August 2016 with a $M_{\mathrm{w}}$ of 6.1 was followed by two seismic events in October 2016 with $M_{\mathrm{w}}$ of 5.9 and 6.5 respectively. The sequence hit a large sector of the Central Apennines of Italy, particularly affecting the Marche and Umbria regions, and significantly damaging several towns. Amongst others, the towns of Amatrice, Norcia and Accumoli were heavily damaged (e.g., [4]).

Many past studies have investigated the effect of the earthquake-induced damage accumulation on several types of structural systems. Generally, damage accumulation can be related to ground-motion duration (e.g., [5, 6] among others) or to the effect of seismic sequences. The seismic performance and vulnerability of structures under seismic sequences has been largely studied in the last decade (e.g., [7, 8, 9, 10]); a detailed review of these past studies is outside the scope of this short paper. However, some general findings can be highlighted. For instance, fairly limited research is available on the effects of aftershocks on advanced computational models, particularly in Europe, using nonlinear time history analyses (NLTHAs). Moreover, most of past studies focused mainly on collapse assessment and/or developing risk assessment frameworks. Also, those past studies mainly used artificial mainshock-aftershock (MS-AS) sequences rather than real (i.e., as recorded) sequences, with limited attention to the development of vulnerability (i.e., loss vs intensity) relationship for mainshock-damaged buildings.

The present study aims to develop fragility curves accounting for both the undamaged and mainshock-damaged states with an attempt of evaluating the effects of real as-recorded MS-AS sequences on the performance and fragility of the case-study structure. In addition, this study considers generating vulnerability relationships considering undamaged and mainshock-damaged states. Such vulnerability relationships express the likelihood that assets at risk will sustain varying degrees of loss (e.g., in terms of direct damage) over a range of aftershock intensity measures (IMs).

The paper is organized as follows. Section 2 discusses the geometric and material properties of the case-study structure; the non-linear modelling strategies used to capture different behavioral patterns of the structure; the definition of damage states; and the selection of groundmotion sequences. Section 3 deals with the seismic performance assessment and derivation of 
fragility curves for the undamaged frames (both in the bare and infilled configurations, under the effects of mainshocks only), followed by a detailed assessment of the infilled frame under the effect of the entire MS-AS sequences, in order to derive conditional fragility relationships taking into account the initial mainshock-induced damage. Vulnerability relationships for the infilled frame are finally derived with a first attempt to also generate vector-valued mainshockaftershock vulnerability relationships for this case-study structure. Section 4 summarizes the main findings from this study.

\section{METHODOLOGY}

\subsection{Case-study structures}

A generic four-story, four-by-four bays RC moment-resisting frame located in Torre del Greco (Naples, Italy) is considered as a case-study index building in this paper. The total height is $13.5 \mathrm{~m}$ with a first story of $4.5 \mathrm{~m}$, upper stories of $3 \mathrm{~m}$ and a bay-width of $4.5 \mathrm{~m}$ in both directions [11]. The frame is designed for gravity loads only and do not conform to modern seismic code requirements. Figure 1 provides the layout and cross-sectional dimensions of the bare frame. Typical average values for the compressive strength of the concrete $\left(f_{\mathrm{cm}}\right)$ and yielding strength of the reinforcements $\left(f_{\mathrm{ym}}\right)$ are assumed; these are equal to $19 \mathrm{MPa}$ and $360 \mathrm{MPa}$ respectively. Infill walls typically used in Southern Italy in the 1970s (e.g., [12]) are considered with the following mechanical properties: compressive strength $\sigma_{\mathrm{m} 0}=2.5 \mathrm{MPa}$; shear strength $\tau_{\mathrm{m} 0}=0.23 \mathrm{MPa}$; Young modulus $E_{\mathrm{m}}=1495 \mathrm{MPa}$ and sliding resistance $\tau_{0}=0.28 \mathrm{MPa}$.

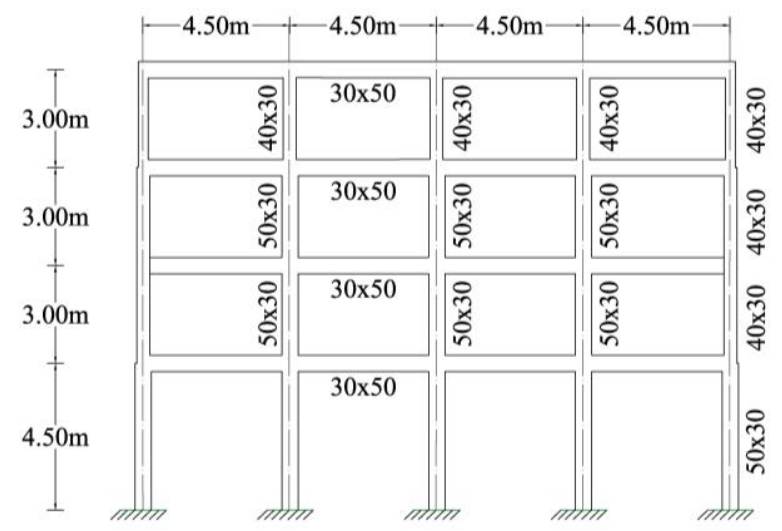

Figure 1: Layouts of the case-study bare frame (cross-sectional dimensions in $\mathrm{cm}$ ).

\subsection{Non-linear modelling}

The seismic response of the case-study structure is simulated by $2 \mathrm{D}$ numerical models in OpenSees [4]. The nonlinear behavior of the structural components is modelled through a lumped plasticity approach for both beams and columns (e.g., [13]). Zero-length rotational springs are assigned at the elements ends and the Ibarra-Medina-Krawinkler model [14], as implemented in OpenSees, is used to describe their moment-rotation nonlinear hysteretic behavior. Model parameters are defined according to [15]. Moreover, in order to capture the possible shear failure, additional shear springs are added in series to the flexural springs. The Setzler and Sezen model [16] is used to define their force-deformation relationship while the initial shear stiffness and the onset peak shear strength are determined accounting for the effects of diagonal cracks as recommended by [17]. Beam-column joints are modelled as rigid while the gravity load and the masses are respectively uniformly distributed on the beams and concentrated at the nodes. 
Masonry infills have been modelled by idealized equivalent struts. The pinching factors for reloading strain and reloading stress and the degradation power of unloading stiffness have been defined according to [18]. The tensile response of the strut was assumed as 5\% of the compressive response as the struts are meant to act in compression only. The force-deformation relationship developed and calibrated by [19] is used to simulate the effect of infills on RC frames. The infills-frame interaction can increase the shear demand on columns leading to brittle shear failure and hence, the equivalent compression struts are modelled by a dual compression struts as suggested by [20]. One strut is diagonal and connects the nodes at the beam-column intersections while the other is an off-diagonal strut connected to the shear springs of the columns. This allows to capture the increase in the columns shear demand due to interaction between the infill walls and RC frame. According to [20], $75 \%$ of the total strut strength and stiffness is assigned to the diagonal strut, whilst $25 \%$ is assigned to the off-diagonal one.

\subsection{Damage State definition and thresholds mapping by pushover analysis.}

Damage States (DSs) describe the damage conditions of a structure under the seismic input. Conventionally, the onset of different DSs can be identified by using thresholds of specific measurable global and/or local Engineering Demand Parameters (EDPs), such as maximum interstory drift ratio (MIDR), maximum top story drift, chord rotation, strength of cross-sections, material strains and others (e.g., [21]).

In this study, MIDR is selected as EDP to represent the global structural performance; MIDR has shown good correlation to both structural and non-structural damage. MIDR thresholds for three different DSs are calibrated based on pushover analyses according to multiple measurable criteria as summarized in Table 1 . The parameters $\theta_{\mathrm{y}}$ and $\theta_{\mathrm{u}}$ of Table 1 denote respectively the yield and the ultimate chord rotations and are defined according to [22] and to the Eurocode 8 Part 3 (EC8-3) [23].

The MIDR thresholds mapping for the DSs is based on [24] and on the EC8-3. The Moderate Damage State (DS1) is characterized by moderate structural and non-structural damages with no significant yielding and members preserve their stiffness and strength. The building in this damage state is occupiable but minor repairs may be required. The Extensive Damage State (DS2) incorporates severe damages in both structural and non-structural components. Buildings retain some residual strength and stiffness to remain stable, require major repairs, which might not be feasible in many cases. The Near-Collapse Damage State (DS3) represents a full exploitation of a building strength and ductility, very low residual strength and stiffness remain after the earthquake and the building is about to collapse. In addition, the Slight Damage State (DS0) is introduced to account for the non-structural damage, which initiate in infill walls due to lateral deformation. This damage state is achieved when the majority of infill walls reach the displacement of first crack.

\begin{tabular}{clll}
\hline Damage Level & \multicolumn{1}{c}{$\begin{array}{c}\text { Moderate } \\
\text { DS1 }\end{array}$} & \multicolumn{1}{c}{$\begin{array}{c}\text { Extensive } \\
\text { DS2 }\end{array}$} & \multicolumn{1}{c}{$\begin{array}{c}\text { Near-Collapse } \\
\text { DS3 }\end{array}$} \\
\hline Section Level & $\begin{array}{l}\text { Reaching yield bending } \\
\text { strength in a column }\end{array}$ & $\begin{array}{l}\text { Max. bending strength } \\
\text { of a column is reached }\end{array}$ & $\begin{array}{l}\text { Reaching shear fail- } \\
\text { ure in any element }\end{array}$ \\
Component & $\begin{array}{l}\text { Reaching the value of } \theta_{\mathrm{y}} \\
\text { in a supporting column }\end{array}$ & $\begin{array}{l}\text { Reaching 75\% of the } \\
\theta_{\mathrm{u}} \text { in any component }\end{array}$ & $\begin{array}{l}\text { Reaching the } \theta_{\mathrm{u}} \text { in } \\
\text { any component }\end{array}$ \\
Global Level & Reaching global yield & $\begin{array}{l}\text { Reaching the maxi- } \\
\text { mum strength }\end{array}$ & $\begin{array}{l}\text { About 20\% drop in } \\
\text { maximum strength }\end{array}$ \\
\hline
\end{tabular}

Table 1. DSs thresholds mapping. 
Structural models are developed for both bare and infilled frames and are characterized respectively by fundamental structural periods of 0.759 and $0.329 \mathrm{sec}$. Pushover analysis is performed to derive DS-thresholds in terms of MIDR based on the damage criteria in Table 1. The pushover incremental load patterns are defined according to the first mode as indicated in the Eurocode 8 (EC8) [25]. Figure 2 reports the results of the pushover analyses by showing the base shear coefficient (i.e., ratio of the total base shear to the weight of the structure) versus the roof drift ratio (i.e., roof displacement normalized by the total building height).

The pushover analysis shows that the story drifts are concentrated in the ground and first stories. The presence of infills worsens the situation and leads to the concentration of deformations in the ground story only. The infills provide a significant contribution in terms of strength and stiffness as reported by Figure 2; however, a significant drop of resistance can be observed due to the concentration of deformation in the ground story. The MIDR thresholds for the DSs are reported in Figure 2 and summarized in Table 2.

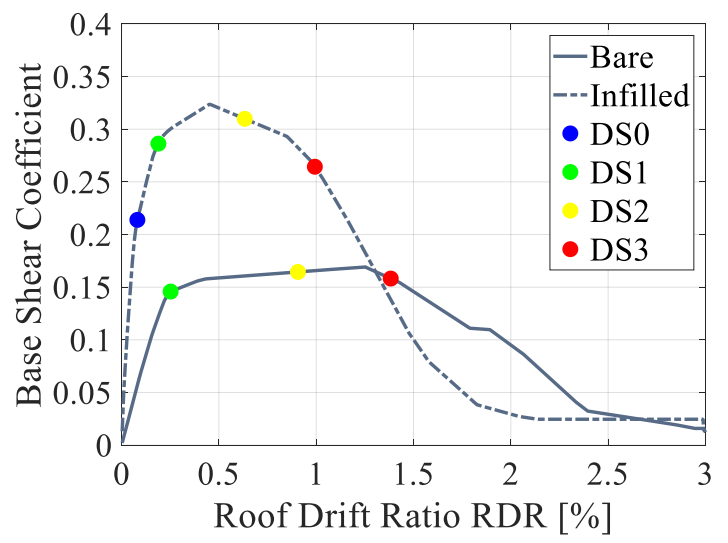

Figure 2. Pushover curves and damage state thresholds for the bare and infilled frames.

\begin{tabular}{cccc}
\hline \multicolumn{4}{c}{ Maximum interstory drift (MIDR) thresholds } \\
\hline $\mathrm{DS}^{*}$ & $\mathrm{DS} 1$ & $\mathrm{DS} 2$ & $\mathrm{DS} 3$ \\
\hline $0.16 \%^{*}$ & $0.38 \%$ & $1.61 \%$ & $2.70 \%$ \\
\hline *DS0 is related to the infilled frame only & &
\end{tabular}

Table 2. MIDR thresholds for the considered DSs.

\subsection{Ground-motion sequence selection}

As discussed earlier, most of the research studies to date have investigated the effects of aftershocks employing artificial MS-AS sequences and using mainshock records within backto-back analyses (e.g., [1]). This procedure assumes that features of aftershocks such as duration, spectral shape and frequency content are similar to the one of the mainshocks, which might yield biased results due to the effects of these features on the seismic performance.

This paper attempts to tackle this issue by considering real (i.e., as-recorded) unscaled MSAS sequences selected from two databases. The first one is the 2012 KKiKSK Ground-Motion Database [26] and is based on the ground motions recorded by the national networks of strong ground-motions $K$-NET/KiK-net ${ }^{1}$. The other source of MS-AS sequences is the NGA-WEST2 Ground Motion Database ${ }^{2}$ developed by the Pacific Earthquake Engineering Research Center.

\footnotetext{
${ }^{1}$ http://www.kyoshin.bosai.go.jp/

2 https://ngawest2.berkeley.edu/
} 
The total number of MS-AS sequences from the two databases is of 703; they have been identified using the criteria discussed in [26]. In the present study, each sequence consists of a mainshock followed by a single aftershock (i.e., the one with the largest magnitude) and the number of sequences was downsized in order to minimize the computational effort required for the analyses. Sequences considered not strong enough to cause structural damages by mainshocks or aftershocks have been disregarded based on the following criteria:

- Only the crustal earthquakes are considered from the $2012 \mathrm{KKiKSK}$ database in order to match the seismogenic nature of the location under consideration (i.e., Italy).

- Sequences with mainshock spectral acceleration at the fundamental period, $S_{a}\left(T_{1}\right)_{M S}$, less than $10 \%$ of the value from the elastic spectrum of EC8 are disregarded as shown in Eq. (1).

$$
\mathrm{S}_{\mathrm{a}}\left(\mathrm{T}_{1}\right)_{\mathrm{MS}} \geq 0.10 \mathrm{~S}_{\mathrm{a}}\left(\mathrm{T}_{1}\right)_{\mathrm{EC} 8}
$$

- All MS-AS sequences having $\mathrm{S}_{\mathrm{a}}\left(\mathrm{T}_{1}\right)_{\mathrm{MS}}$ greater than 10 times $\mathrm{S}_{\mathrm{a}}\left(\mathrm{T}_{1}\right)_{\mathrm{EC} 8}$ are disregarded as shown in Eq. (2).

$$
\mathrm{S}_{\mathrm{a}}\left(\mathrm{T}_{1}\right)_{\mathrm{MS}} \leq 10 \mathrm{~S}_{\mathrm{a}}\left(\mathrm{T}_{1}\right)_{\mathrm{EC} 8}
$$

- Aftershocks that are not strong enough might not result in damage increase in a mainshockdamaged structure, meaning that the structure will likely remain in the same initial damage state caused by a mainshock. Accordingly, all MS-AS sequences with, $\mathrm{S}_{\mathrm{a}}\left(\mathrm{T}_{1}\right)_{\text {AS }}$ less than $50 \%$ of $\mathrm{S}_{\mathrm{a}}\left(\mathrm{T}_{1}\right)_{\mathrm{MS}}$ are disregarded.

$$
\frac{\mathrm{S}_{\mathrm{a}}\left(\mathrm{T}_{1}\right)_{\mathrm{AS}}}{\mathrm{S}_{\mathrm{a}}\left(\mathrm{T}_{1}\right)_{\mathrm{MS}}} \geq 50 \%
$$

According to the described criteria to the 2012 KKiKSK and NGA-WEST2 databases reduced the number of MS-AS sequences from 703 to: 255 for the bare frame and 358 for the infilled frame (due to their different fundamental periods). Figure 3 reports the scatter of the $S_{a}\left(T_{1}\right)_{M S}$ versus $S_{a}\left(T_{1}\right)_{A S}$ values for the selected sequences.
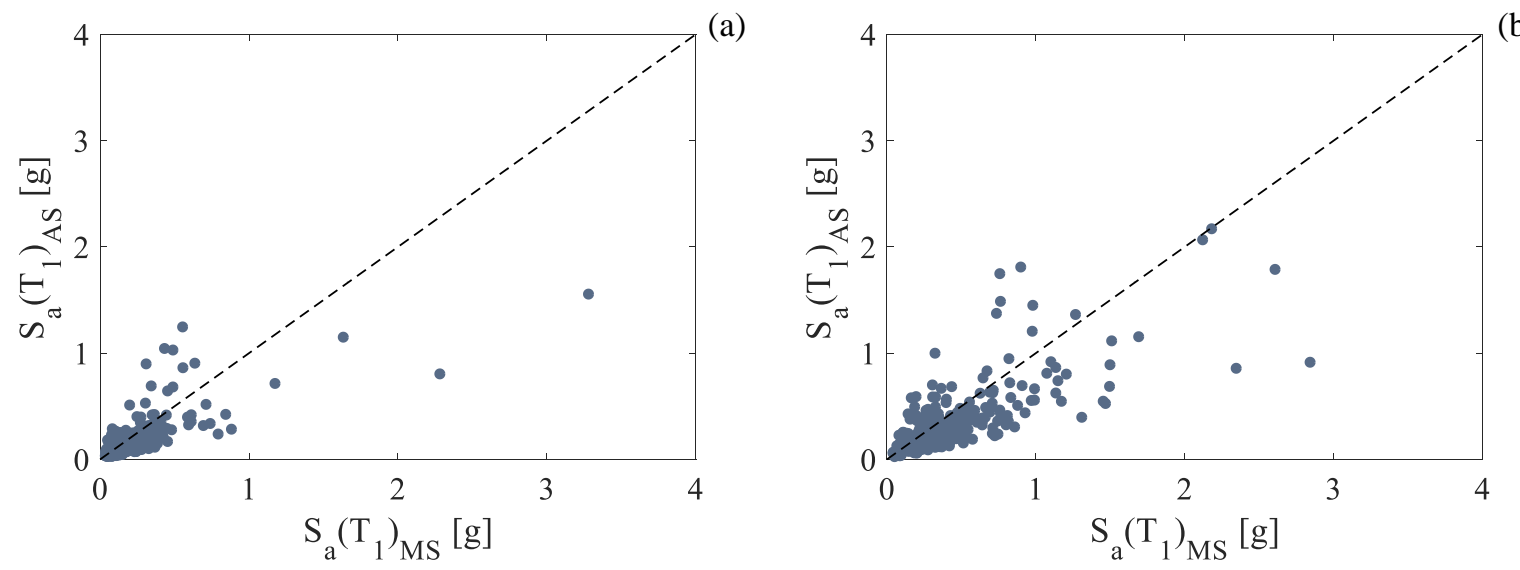

Figure 3. Scatter of $S_{a}\left(T_{1}\right)_{M S}$ and $S_{a}\left(T_{1}\right)_{A S}$ for the (a) bare frame and (b) infilled frame.

\subsection{Cloud analysis and fragility curves derivation.}

NLTHAs are performed on the case-study structures by using the set of unscaled groundmotion records discussed above. This produces a cloud of points in terms of ground motion IM and the corresponding EDP values (i.e., a cloud of IM vs EDP pairs) [27]. Probabilistic Seismic Demand Model (PSDM) are successively obtained by fitting the results of the Cloud analysis 
with a power law model (i.e., a linear regression in the bilogarithmic space) allowing the derivation of fragility curves by a closed form solution (e.g., [21]). Fragility curves represent the conditional probability of exceeding a specific damage state given the level of IM [27]. As previously discussed, MIDR is assumed as EDP to represent the structural response while the $5 \%$-damped (pseudo-)spectral acceleration at the fundamental structural period, $\mathrm{S}_{\mathrm{a}}\left(\mathrm{T}_{1}\right)$, is the assumed IM.

\subsection{Vulnerability functions.}

Vulnerability functions are widely used in seismic risk assessment of building portfolios. They can be effectively used to compute seismic losses (economic losses, downtime and casualties) for various earthquake scenarios and ground-motion IM values [28]. The vulnerability functions developed in this study address only direct economic losses; in fact, they are expressed in terms of loss ratio (LR), i.e., the ratio of cost of repair to cost of replacement for a give asset, conditional on the level of ground-shaking intensity. Such functions can be derived by combining fragility curves, which provide the probability of attaining specific DSs given the IM, with consequence functions (or damage-to-loss ratios, DF) using the total probability theorem [28], as reported in Eq. (4).

$$
\mathrm{LR}(\mathrm{IM})=\sum_{i=1} \mathrm{DF}_{i} \mathrm{P}\left(\mathrm{DS}=\mathrm{ds}_{i} \mid \mathrm{IM}\right)
$$

$\mathrm{DF}_{i}$ is the damage-to-loss ratio for a given damage level $\mathrm{ds}_{i}$ (e.g., [29]). These ratios are region and building-type-specific and must be carefully selected (e.g., [30]).

The model proposed by [31] is used in this paper in order to develop vulnerability functions. This model provides the damage-to-loss ratios for Italy and for different DSs based on the MSK-76 intensity scale (e.g., [32]). Table 3 shows the damage-to-loss ratios estimated by the author for six different DSs.

\begin{tabular}{ccccccc}
\hline Damage State & DS0 & DS1 & DS2 & DS3 & DS4 & DS5 \\
\hline Damage-to-loss ratio & 0 & 0.01 & 0.10 & 0.35 & 0.75 & 1.00 \\
\hline
\end{tabular}

Table 3. Damage-to-loss ratios for five DSs [31]

\section{PERFORMANCE-BASED ASSESSMENT RESULTS}

\subsection{Performance assessment of undamaged structures}

The case-study building is first subjected to the selected mainshocks to assess its performance considering the undamaged state. Figure 4 shows the results of NLTHA (i.e., $\mathrm{S}_{\mathrm{a}}\left(\mathrm{T}_{1}\right)_{\mathrm{MS}}$ vs. MIDRs) and the PSDMs for the bare and the infilled case-study frames. It can be observed that both structures remain undamaged in several analysis cases, which constitute $46 \%$ of the cases for the bare frame and 30\% for the infilled frame (i.e., the ND-cases in Figure 4). Similarly, in several instances, the structures experience either DS1 or DS2; specifically, 52\% for the bare frame and $30 \%$ for the infilled. The near-collapse damage state (i.e., DS3) is also attained in 2\% of the analysis cases for the bare frame and $3 \%$ for the infilled frame. The positive contribution of infills can be observed as the same levels of damage are observed for higher values of IM compared to the bare frame. 

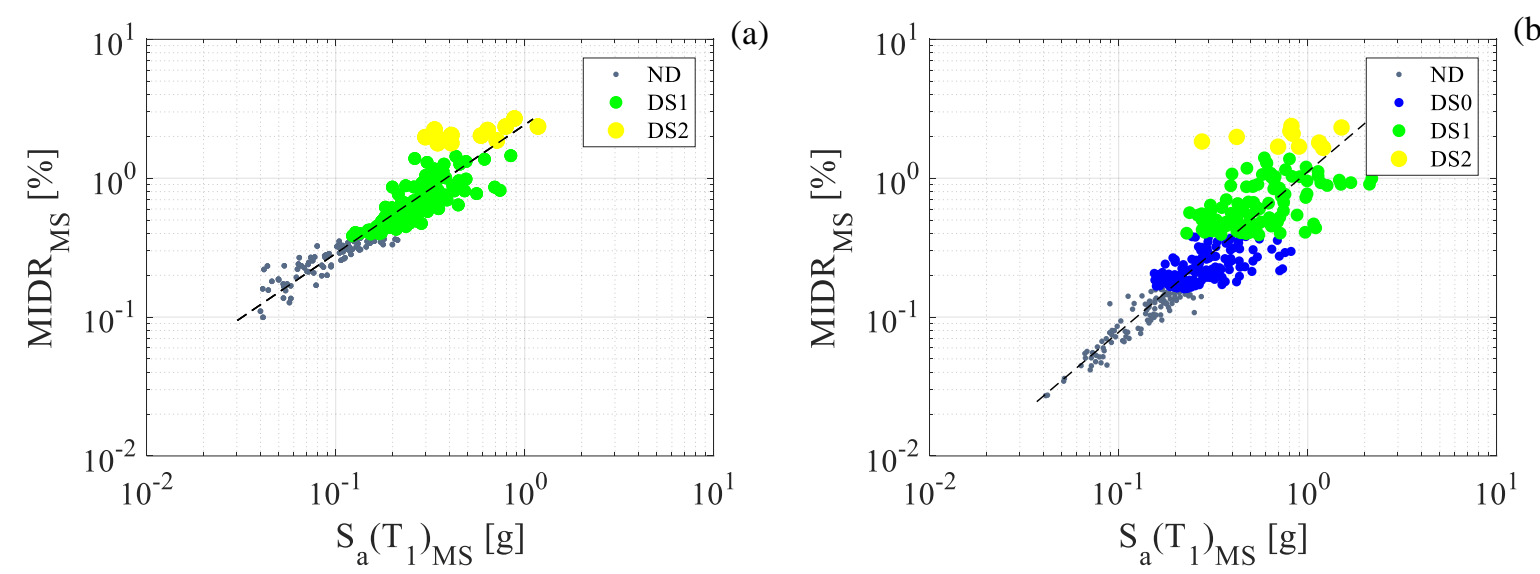

Figure 4. Undamaged state cloud analysis and Probabilistic Seismic Demand Models (i.e., $\mathrm{S}_{\mathrm{a}}\left(\mathrm{T}_{1}\right)_{\mathrm{MS}}$ vs. MIDR) for (a) bare and (b) infilled frames.

Fragility curves are successively derived and are reported in Figure 5. The comparison shows that the infills are damaged (i.e., DS0) for relatively low values of IM; on the other side, the infills contribute to the overall resistance of the frame and, the median IM values for DS1, DS2 and DS3 are significantly higher with respect to the ones of the bare frame. The median of IM values $\left(\theta_{\mathrm{IM}}\right)$ and the standard deviation $\left(\sigma_{\mathrm{InIM}}\right)$ for each DS are also given in Table 4.

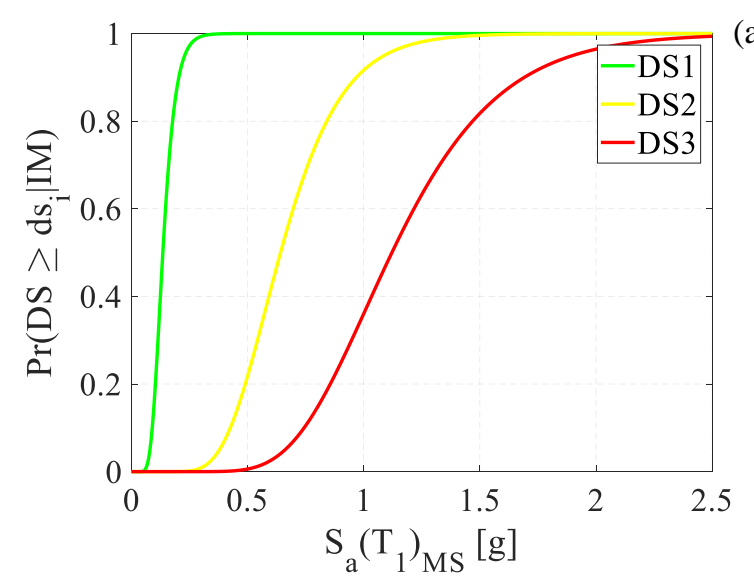

(a)

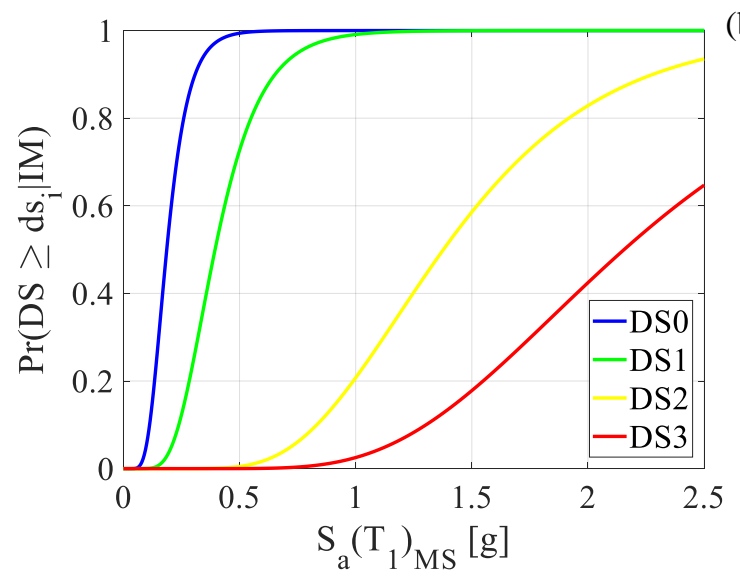

(b)

Figure 5. Undamaged state fragility functions for (a) bare and (b) infilled frames.

\begin{tabular}{ccccc}
\hline Frame type & \multicolumn{2}{c}{ Bare frame } & \multicolumn{2}{c}{ Infilled frame } \\
\cline { 2 - 5 } Damage State & $\theta_{\mathrm{IM}}[\mathrm{g}]$ & $\sigma_{\mathrm{InIM}}[\mathrm{g}]$ & $\theta_{\mathrm{IM}}[\mathrm{g}]$ & $\sigma_{\mathrm{InIM}}[\mathrm{g}]$ \\
\hline DS0 & - & - & 0.187 & \\
DS1 & 0.136 & & 0.396 & 0.3906 \\
DS2 & 0.698 & 0.3064 & 1.392 & \\
DS3 & 1.254 & & 2.184 & \\
\hline
\end{tabular}

Table 4. Undamaged state fragility functions. Median and standard deviation values.

\subsection{Performance assessment of mainshock-damaged structures}

For the sake of brevity, the following part of the study is limited to the assessment of the MS-AS performance of the infilled frame only. This model is more representative of actual building structures and allows a more realistic evaluation of their vulnerability. To simulate the 
seismic performance of the mainshock-damaged structure during the aftershocks, the infilled frame is subjected to the entire MS-AS sequences. It should be noted that 40 seconds of free vibration are added to all MS-AS sequence after the mainshocks to allow the structure to reach the rest conditions prior to subjecting it to the aftershocks. Figure 6(a) shows the MIDR values attained due to the mainshocks versus the MIDR values obtained during the aftershocks for all analysis cases. The points located above the dashed diagonal line represent the cases in which the MIDR values due to the aftershock are higher than the corresponding values obtained due to the mainshocks only. Figure 6(a) shows that in several cases the frame experienced higher damage states as consequence of the MS-AS sequence with respect to the mainshock only. For instance, several observations in which the frame remains undamaged after the mainshocks, showed that it attains DS0 after the aftershocks. Similar situation can be observed with the frame passing from DS0 to DS1. For a few cases Figure 6(a) shows an increase in the damage state from DS1 to DS2, with only one observation for which the frame reached the collapse (DS3) after being initially in the DS2 range. However, the number of damage state increase observations is not statistically significant to derive fragility curves.

In order to increase the number of damage state increase observations, a back-to-back analysis (e.g., [33]) is also performed. For each of the three DSs, the most 'critical' five mainshocks causing MIDR values immediately below each DS-threshold were selected and then combined with the other mainshocks generating 2005 artificial sequences. Only the ground motions coming from the same database and sharing the same processing are combined together to perform back-to-back analyses.

This process allowed the definition of a statistically significant number of DS increases due to sequential ground motions, allowing the definition of state-dependent fragility functions. PSDMs are developed by filtering the points in the cloud and considering only the cases in which the MIDR of the aftershocks is higher than the MIDR of the mainshocks. Accordingly, Figure 6(b) shows the fragility curves for the undamaged structure together with the state-dependent fragility functions considering the DS3 conditioned to both DS1 and DS2 and DS2 conditioned to DS1.

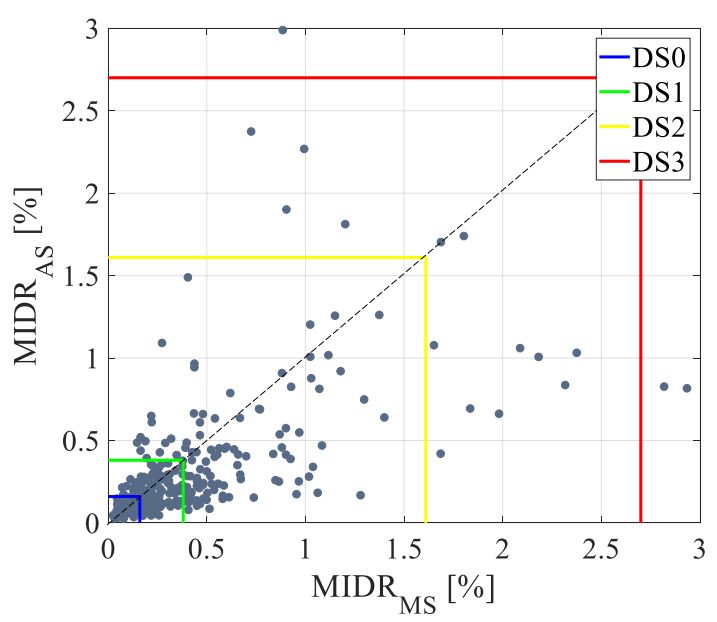

(a)

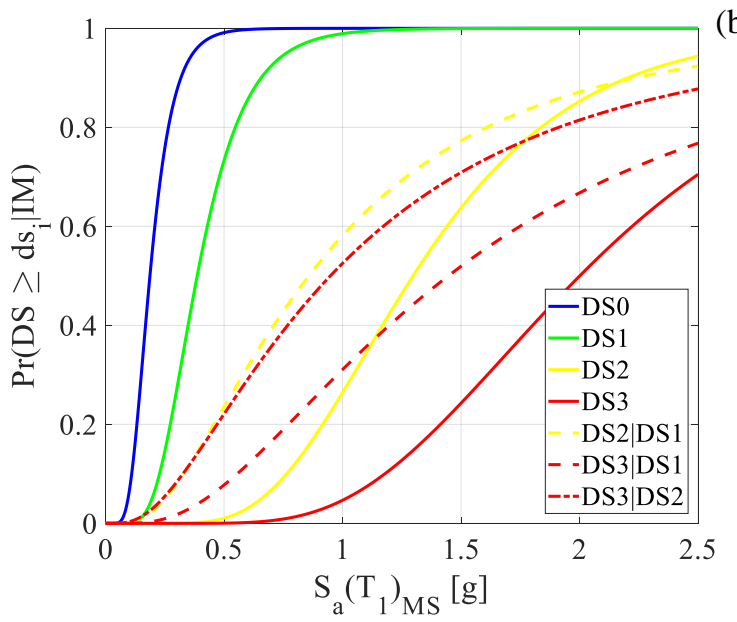

(b)

Figure 6. (a) MIDR values due to the mainshocks vs. aftershocks for the bare frame considering real sequences. (b) State-dependent fragility functions for the infilled frame.

Figure 6(b) shows the increased fragility of the frame as consequence of the mainshocksinduced damage. $\theta_{\mathrm{IM}}$ of DS2 and DS3 are significantly reduced by $38.4 \%$ and $33.7 \%$ respectively when the structure has an initial damage of DS1 due to mainshocks. The reduction in $\theta_{\mathrm{IM}}$ for DS3 when the structure has an initial damage of DS2 reach values of $56.6 \%$. 


\subsection{Vulnerability assessment of undamaged and mainshock-damaged structure.}

Vulnerability functions are finally developed, allowing the evaluation of expected seismic losses conditioned to the mainshock and aftershock IM values. As discussed above, the damageto-loss ratios defined by [31] are used in this study. The original study [31] considered five DSs plus the undamaged state while the present study considers three DSs only plus the undamaged state. In order to couple the damage-to-loss ratios with the developed fragility curves, a matching of the different DSs was performed and is reported in Table 5.

\begin{tabular}{llcccccc}
\hline Di Pasquale & DSs & DS0 & DS1 & DS2 & DS3 & DS4 & DS5 \\
et al. $(2005)$ & Damage Factor & 0.00 & 0.01 & 0.10 & 0.35 & 0.75 & 1.00 \\
\hline Infilled & DSs & \multicolumn{2}{c}{ DS0 } & DS1 & DS2 & DS3 \\
frame & Damage Factor & \multicolumn{2}{c}{0.01} & 0.1 & 0.55 & 1.00 \\
\hline
\end{tabular}

Table 5. Matching Damage Factors from [31] and the present study for infilled frames.

The probabilities of each DSs conditioned to the IM values are combined with the damageto-loss ratios in order to produce conditional vulnerability functions as specified in Eq. (4). Figure 7(a) shows the vulnerability functions for the infilled frame in the undamaged state and with mainshock-induced DS1 and DS2. The undamaged structure has a loss ratio of about $80 \%$ with an $\mathrm{S}_{\mathrm{a}}\left(\mathrm{T}_{1}\right)_{\mathrm{AS}}$ equal to $2.5 \mathrm{~g}$. Differently, the structure experiences similar losses, and even higher, at significantly lower $S_{a}\left(T_{1}\right)_{A S}$ intensities when the mainshock-induced damage is already in place. For instance, the infilled frame has a loss ratio of $90 \%$ with values of $S_{a}\left(T_{1}\right)_{A S}$ equal to $2.11 \mathrm{~g}$ and $0.69 \mathrm{~g}$ respectively under the initial mainshock-induced DS1 and DS2.

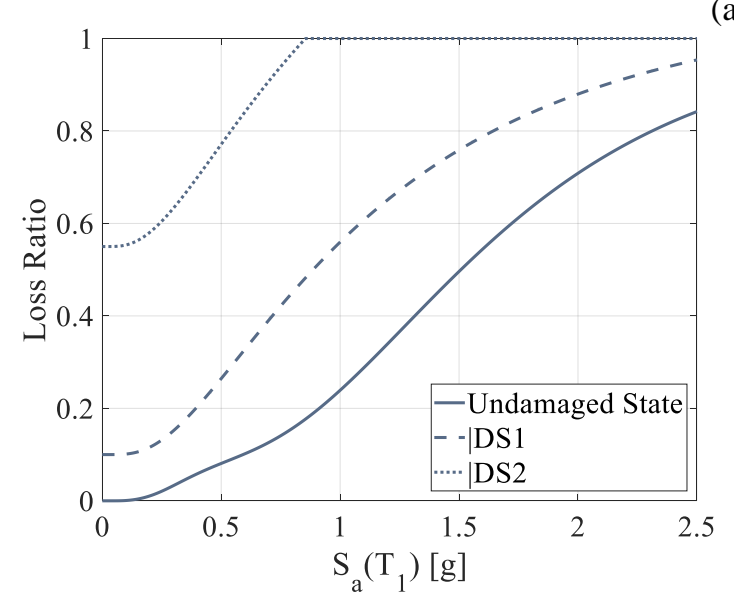

(a)

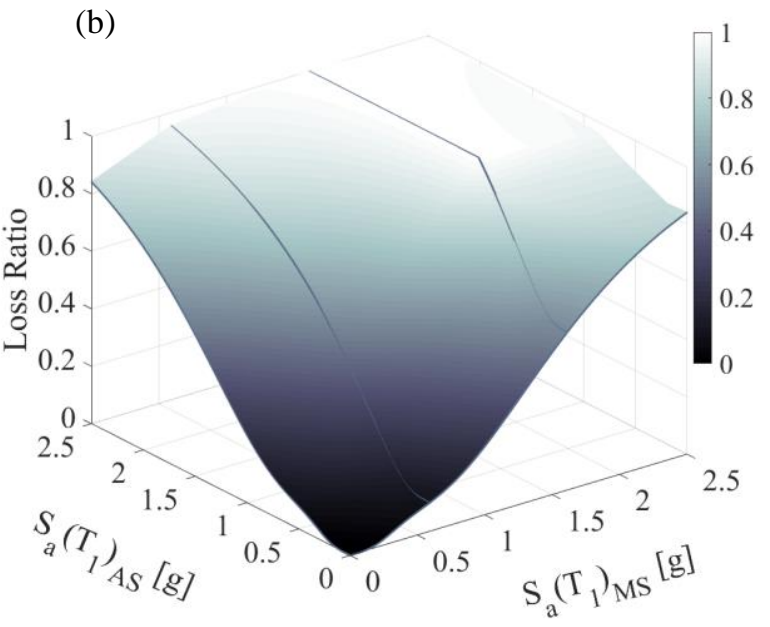

Figure 7. Vulnerability functions for the infilled frame.

State-dependent vulnerability functions can be also represented by plotting vulnerability surfaces, as discussed in [33]. The IMs of the mainshocks and aftershocks are plotted on the horizontal axes, while the vertical axis shows the resulting loss ratio. It should be noted that the surface passes through the state-dependent vulnerability functions, which are fixed at their intersection with the undamaged-state vulnerability function. The intermediate points between these functions are estimated using linear interpolation of 3D scatter of points. The vulnerability surface reported in Figure 7(b) allows to easily estimate the final expected losses based on $\mathrm{S}_{\mathrm{a}}\left(\mathrm{T}_{1}\right)_{\mathrm{MS}}$ and $\mathrm{S}_{\mathrm{a}}\left(\mathrm{T}_{1}\right)_{\text {AS. }}$. However, as per the initial assumption, only one single aftershock is 
considered at this stage. The proposed vulnerability surfaces can be more easily implemented into a time-dependent risk assessment framework.

\section{CONCLUSIONS}

This study investigated the performance of a four-story nonductile RC frame, in both bare and infilled configurations, against MS-AS ground-motion sequences. 2D advanced nonlinear models were created using OpenSees, accounting for flexural and shear hysteretic behaviors in addition to the presence of masonry infill walls. Real MS-AS sequences as well as artificial sequences were adopted to carry out nonlinear time history analysis via a cloud-based approach. Fragility curves for the undamaged frames were first developed from mainshock analysis, highlighting the positive impact of the infills on the seismic performance of the case-study structure. Subsequently, state-dependent fragility functions were derived for the mainshock-damaged infilled frame based on the analysis results of the full MS-AS sequences. Results demonstrated that the mainshock-induced damage leads to significantly higher fragility compared to the structure in the undamaged state. It was also shown that higher initial damage caused by the mainshocks leads to larger fragility of the structure against aftershocks.

Vulnerability functions were finally developed for the infilled frame based on the results of fragility analysis in conjunction with damage-to-loss models calibrated on Italian post-earthquake data. These functions illustrated how the expected losses for the frame in the mainshockdamaged configuration are considerably higher than those for the undamaged-state frame across the entire range of ground-motion intensities. Vector-valued mainshock-aftershock vulnerability relationships were also generated in the form of a three-dimensional vulnerability surface that can be adopted to quantify the expected seismic losses based on the level of intensity of both mainshocks and aftershocks.

\section{ACKNOWLEDGEMENTS}

This research is supported by UGC-UKIERI joint research programme at Indian Institute of Technology Bombay and University College of London (Grant No. 2017-UGC-10070). The support is gratefully acknowledged. The authors would like to acknowledge Dr. Katsuichiro Goda, at The University of Western Ontario, Canada, for sharing the real ground-motion sequences adopted in this study and details about their selection. The authors are very grateful to Prof. Paolo Bazzurro, at the Istituto Universitario di Studi Superiori (IUSS), Pavia, for the discussion and his constructive comments on an earlier version of this work.

\section{REFERENCES}

[1] Y. Li, R. Song, J.W. van de Lindt, Collapse Fragility of Steel Structures Subjected to Earthquake Mainshock-Aftershock Sequences. Journal of Structural Engineering, 140(12), 1-10, 2014.

[2] W.Y. Kam, S. Pampanin, K. Elwood, Seismic performance of reinforced concrete buildings in the 22 February Christchurch (Lyttelton) earthquake. Bulletin of the New Zealand Society for Earthquake Engineering, 44(4), 239-278, 20111.

[3] P. Zimmaro, J.P. Stewart, Engineering Reconnaissance Following the October 2016 Central Italy Earthquakes Version 2. Geotechnical Extreme Events Reconnaisance Assosiation (GEER), Report No. GEER-050D, 2017. 
[4] S. Mazzoni, F. McKenna, M.H. Scott, G.L. Fenves, Open system for earthquake engineering simulation user command-language manual, OpenSees Version 2.0, University of California, Berkeley, CA, 2009.

[5] M. Raghunandan, A.B. Liel, Effect of ground motion duration on earthquake-induced structural collapse. Strucrtural Safety, 41, 119-133, 2013.

[6] J. Ghosh, J.E. Padgett, M. Sánchez-Silva, Seismic Damage Accumulation in Highway Bridges in Earthquake-Prone Regions. Earthquake Spectra, 31(1), 115-135, 2015.

[7] M. Raghunandan, A.B. Liel, N. Luco, Aftershock collapse vulnerability assessment of reinforced concrete frame structures. Earthquake Engineering and Strucrtural Dynamics, 44, 419-439, 2015.

[8] G.D. Hatzigeorgiou, A.A. Liolios, Nonlinear behaviour of RC frames under repeated strong ground motions. Soil Dynamics and Earthquake Engineering, 30(10), 1010-1025, 2010 .

[9] L. Di Sarno, Effects of multiple earthquakes on inelastic structural response. Engineering Structures, 56, 673-681, 2013.

[10] H.V. Burton, M. Sharma, Quantifying the Reduction in Collapse Safety of Main ShockDamaged Reinforced Concrete Frames with Infills. Earthquake Spectra, 33(1), 25-44, 2017.

[11] S. Minas, C. Galasso, Accounting for spectral shape in simplified fragility analysis of case-study reinforced concrete frames. Soil Dynamics and Earthquake Engineering, 119, 91-103, 2019.

[12] G. Uva, F. Porco, A. Fiore, Appraisal of masonry infill walls effect in the seismic response of RC framed buildings: A case study. Engineering Structures, 34, 514-526, 2012.

[13] G.G. Deierlein, A.M. Reinhorn, M.R. Willford, Nonlinear structural analysis for seismic design. NEHRP Seismic Design Technical Brief No. 4. Gaithersburg, MD, NIST GCR 10-917-5: produced by the NEHRP Consultants Joint Venture, a partnership of the Applied Technology Council and the Consortium of Universities for Research in Earthquake Earthquake Engineering, for the National Institute of Standards and Technology, 2010.

[14] L.F. Ibarra, R.A. Medina, H. Krawinkler, Hysteretic models that incorporate strength and stiffness deterioration. Earthquake Engineering and Structural Dynamics, 34, 1489-1511, 2005.

[15] C.B. Haselton, A.B. Liel, S.T. Lange, G.G. Deierlein, Calibration of Model to Simulate Response of Reinforced Concrete Beam-Columns to Collapse. ACI Structural Journal, 113(6), 1141-1152, 2016.

[16] E.J. Setzler, H. Sezen, Model for the Lateral Behavior of Reinforced Concrete Columns Including Shear Deformations. Earthquake Spectra, 24(2), 493-511, 2008.

[17] M. Gerin, P. Adebar, Simple Rational Model for Reinforced Concrete Subjected to Seismic ShearAccounting for shear in seismic analysis of concrete structures. Journal of Structural Engineering, 135(7), 753-761, 2009.

[18] N. Noh Mohammad, L. Liberatore, F. Mollaioli, S. Tesfamariam, Modelling of masonry infilled RC frames subjected to cyclic loads: State of the art review and modelling with OpenSees. Engineering Structures, 150, 599-621, 2017. 
[19] L. Liberatore, L.D. Decanini, Effect of infills on the seismic response of high-rise RC buildings designed as bare according to Eurocode 8. Ingegneria Sismica, 28(3), 7-23, 2011.

[20] H. Burton, G. Deierlein, Simulation of Seismic Collapse in Nonductile Reinforced Concrete Frame Buildings with Masonry Infills. Journal of Structural Engineering, 140(8),1-10, 2014.

[21] F. Freddi, J.E. Padgett, A. Dall'Asta, Probabilistic seismic demand modeling of local level response parameters of an RC frame. Bulletin of Earthquake Engineering, 15(1), 123, 2017.

[22] T.B. Panagiotakos, M.N. Fardis, Deformations of Reinforced Concrete Members at Yielding and Ultimate. ACI Structural Journal, 98(2), 135-148, 2001.

[23] EN 1998-3, Eurocode 8: Design of structures for earthquake resistance - Part 3: Assessment and retrofitting of buildings. European Standard EN 1998-3. European Committee for Standardization (CEN), Brussels, Belgium, 2005.

[24] T. Rossetto, P. Gehl, S. Minas, C. Galasso, P. Duffour, J. Douglas, O. Cook, FRACAS: A capacity spectrum approach for seismic fragility assessment including record-to-record variability. Engineering Structures, 125, 337-348, 2016.

[25] EN 1998-1, Eurocode 8: Design of structures for earthquake resistance. Part 1: General rules, seismic action and rules for buildings. European Standard EN 1998-1. European Committee for Standardization (CEN), Brussels, Belgium, 2004.

[26] K. Goda, F. Wenzel, R. De Risi, Empirical assessment of nonlinear seismic demand of mainshock-aftershock ground motion sequences for Japanese earthquakes. Frontiers in Built Environment, 1, 6, 2015.

[27] C.A. Cornell, F. Jalayer, R.O. Hamburger, D.A. Foutch, Probabilistic basis for 2000 SAC Federal Emergency Management Agency steel moment frame guidelines. Journal of Structural Engineering, 128(4), 526-533, 2002.

[28] T. Rossetto, I. Ioannou, D.N. Grant, T. Maqsood, Guidelines for empirical vulnerability assessment, GEM Technical Report 2014-08 V1.0.0, 140 pp., GEM Foundation, Pavia, Italy, doi: 10.13117/ GEM.VULN-MOD.TR2014.11, 2014.

[29] M. Hill, T. Rossetto, Comparison of building damage scales and damage descriptions for use in earthquake loss modelling in Europe. Bulletin of Earthquake Engineering, 6(2), 335-365, 2008.

[30] T. Rossetto, A. Elnashai, Derivation of vulnerability functions for European-type RC structures based on observational data. Engineering Structures, 25(10), 1241-1263, 2003.

[31] G. Di Pasquale, G. Orsini, R.W. Romeo, New Developments in Seismic Risk Assessment in Italy. Bulletin of Earthquake Engineering, 3, 101-128, 2005.

[32] R.M. Musson, G. Grünthal, M. Stucchi, The comparison of macroseismic intensity scales. Journal of Seismology, 14(2), 413-428, 2010.

[33] P.A.G. de Quevedo Iñarritu, Effects of aftershock damage on masonry building vulnerability, A Dissertation submitted in partial fulfilment of the requirements for the Master degree in Earthquake Engineering \& Engineering Seismology, Pavia: Istituto Universitario di Studi Superiori di Pavia, 2018. 